\title{
Aplicação de agentes para o controle de pendências geradas nos processos de workflow
}

\author{
Fabiane A. Frantz, Daniela D. S. Bagatini, Kurt W. Molz \\ Departamento de Informática - Universidade de Santa Cruz do Sul (UNISC) \\ Av. Independência, 2293 - 96.815-900 - Santa Cruz do Sul - RS - Brazil \\ fabianefrantz@ibestvip.com.br, \{bagatini, kurt\}@unisc.br
}

\begin{abstract}
In this work, the study and modeling of a workflow-based business process is performed, in order to identify those places where exceptions that cause pendencies on the business process, might occur. Based on this study, this work proposes a new workflow model, which brings several tasks, such as: - agents definition; model workflow properties in a existing workflow tool; implement the necessary agents in a simulation environment, in order to prevent pendencies on the business process.

Resumo. O presente trabalho tem por objetivo o estudo e a modelagem de um processo de negócio, utilizando como base um modelo de workflow, com a finalidade de identificar os locais onde ocorrem exceções no processo que ocasionam pendências. Com base nesse estudo, propor um novo modelo de workflow, incluindo agentes, realizar a modelagem do modelo proposto em uma ferramenta de workflow e implementar os agentes em um ambiente de simulação, no intuito de prevenir tais pendências.
\end{abstract}

\section{Introdução}

Workflow é uma tecnologia capaz de controlar as atividades que compõem os processos de negócios de uma organização, com a finalidade de permitir um maior controle sobre suas tarefas e procedimentos [Cruz 2003]. Um sistema de workflow obtém maior sucesso quando implementados sobre processos bem definidos, cujas atividades são bastante previsíveis e não costumam desviar-se de um certo padrão [Cruz 2004]. Porém, em uma organização, isso nem sempre é possível, visto que podem surgir situações em que novas atividades devam ser realizadas para restabelecer o seu pleno andamento. Para referir-se a estas exceções que ocorrem nos processos, neste trabalho adotou-se o termo pendências.

O controle de pendências em um workflow pode tornar-se uma tarefa um tanto difícil em organizações que possuem muitas exceções em seus processos. Por esse motivo, o presente trabalho tem como objetivo descrever uma solução adotada para evitar que essas pendências ocorram, procurando tornar o sistema mais eficiente. Para tanto, optou-se por uma solução baseada em agentes aplicada a um estudo de caso, no qual tais agentes têm por meta monitorar atividades do processo e evitar que pendências sejam geradas no processo de negócio da organização, proporcionando um melhor fluxo de trabalho.

Em um ambiente multiagente, os agentes são capazes de interagir de modo a cooperar para que uma determinada meta seja alcançada de maneira satisfatória, semelhante ao que ocorre com a própria sociedade humana, onde pessoas que 
compartilham um objetivo comum e um senso de equipe conseguem desempenhar seu trabalho mais depressa e facilmente [Ogliari 2005]. Considerando as características e propriedades dos agentes (autonomia, habilidade social, capacidade de reação e comunicação, entre outras), torna-se possível uma solução baseada em agentes para o problema acima descrito [Juchem 2002] e [Hübner 2003].

Assim, este artigo apresenta a modelagem de um workflow adicionando agentes ao modelo, no intuito de prevenir pendências.

\section{Um Sistema Multiagente Aplicado a Processos de Negócios}

Adotou-se como modelo para o estudo de processos e suas pendências uma indústria do ramo metalúrgico, localizada na cidade de Santa Cruz do Sul, Rio Grande do Sul. O foco deste estudo de caso foi o setor de logística. A escolha por esse setor se justifica por ser a logística uma área em grande expansão e, que na indústria modelo, está recebendo uma atenção cada vez maior, devido à desvantagem da indústria com relação aos seus principais concorrentes: a sua distância ao centro do país, ou seja, o local onde o produto é manufaturado é distante de onde é consumido.

Dentre as atribuições do setor de logística destaca-se a sua função de controlar a entrega de mercadoria no cliente. Uma atribuição difícil, pois não depende somente do pessoal interno da indústria, envolve transportadoras, agregados e o próprio cliente.

\subsection{Pendências do processo de entrega}

No processo de entrega de mercadorias podem ocorrer várias pendências. A Tabela 1 apresenta as principais pendências originadas na entrega, causas e conseqüências.

Tabela 1 - Pendências do processo de entrega de mercadoria.

\begin{tabular}{|c|l|l|}
\hline Pendência & \multicolumn{1}{|c|}{ Motivo (causa) } & \multicolumn{1}{c|}{ Conseqüências } \\
\hline Recusa & $\begin{array}{l}\text { atraso na entrega, desacordo com o } \\
\text { pedido, pedido cancelado, sem pedido, } \\
\text { avaria, troca ou falta de volumes }\end{array}$ & $\begin{array}{l}\text { prorrogação de duplicatas, correção do pedido, } \\
\text { recolocação em outro cliente, troca ou reposição de } \\
\text { mercadoria, devolução de mercadoria }\end{array}$ \\
\hline Sinistro & roubo ou acidente & $\begin{array}{l}\text { enviar nova mercadoria, solicitar reembolso da } \\
\text { seguradora }\end{array}$ \\
\hline $\begin{array}{c}\text { Mercadoria } \\
\text { não entregue }\end{array}$ & $\begin{array}{l}\text { cliente não localizado, pagamento de } \\
\text { ICMS antecipado }\end{array}$ & $\begin{array}{l}\text { confirmar endereço do cliente, solicitar pagamento do } \\
\text { ICMS, recolocação em outro cliente, retorno da } \\
\text { mercadoria }\end{array}$ \\
\hline
\end{tabular}

Dos itens descritos na Tabela 1 , a recusa é a pendência que ocorre com maior freqüência, e seus motivos são bem variados, conforme apresentado na tabela. Uma recusa pode causar muitos transtornos, envolvendo o trabalho de muitas pessoas e gerando custos desnecessários.

As recusas de mercadorias acontecem com maior freqüência nos clientes grandes redes ${ }^{1}$, devido ao fato de possuírem muitas regras. Nesses casos, a solução da pendência se torna mais complicada em função do alto número de burocracias existentes. Por exemplo: quando ocorre uma recusa, normalmente a indústria é informada quando a transportadora já não está mais no cliente. A informação poderá chegar para a indústria

${ }^{1}$ Os clientes grandes redes normalmente concentram uma fatia significativa do faturamento da indústria envolvendo contrato de fornecimento. Nesses contratos devem ser observadas algumas regras, as quais, se não forem cumpridas, podem gerar problemas como: cancelamento do pedido e, em alguns casos, multa. Dentre essas regras está o cumprimento da data estabelecida para a entrega de mercadorias. 
até alguns dias após a recusa. A essa altura o pedido deverá estar cancelado, sendo necessário entrar em contato com o comprador, o qual decidirá se poderá ou não ajudar na solução do problema. Não havendo um acordo, a indústria pode tentar uma recolocação da mercadoria em outro cliente e, em último caso, solicitar a transportadora o retorno da mercadoria. Até que a pendência seja solucionada, pode levar alguns dias.

Pode-se constatar através desse fato, que uma simples recusa de mercadoria desencadeia um processo no qual muitas pessoas são envolvidas na busca de sua solução. É importante ressaltar ainda que conforme o tipo de mercadoria, pode ser necessário, por exemplo, trocar a embalagem do produto, pelo fato da mesma não estar mais em condições de venda. Isto demanda em custos de embalagem e de mão de obra de retrabalho.

\subsection{Workflow proposto}

Baseado nos problemas expostos apresenta-se um modelo de fluxo de trabalho, com papéis ocupados por agentes [Frantz 2005]. Os agentes têm a função de evitar que ocorram pendências na entrega das mercadorias para os clientes grandes redes, desempenhando o papel de monitoramento das entregas. Além disso, eles podem informar qualquer alteração no pedido no momento em que o mesmo ocorre, como um cancelamento, embora nem sempre possa ser evitado, permitem que a indústria tenha $o$ conhecimento do fato, independente do recebimento da informação por parte da transportadora. Os agentes também podem intermediar renegociações como uma nova data de entrega, no caso de um possível atraso na entrega.

A Figura 1 apresenta um modelo de workflow (lado da indústria), adotando o paradigma de agentes. Na figura é possível visualizar os papéis do agente indústria (Ag_Ind) e assistente (Ind). O agente cliente faz parte do ambiente do cliente.

Através do monitoramento dos pedidos, os agentes poderão, detectar problemas em fase inicial, ou seja, podem evitar que pequenos problemas como um cancelamento de pedido se transformem em grandes pendências. Por exemplo: caso ocorra o cancelamento de um pedido por parte do cliente, o agente cliente poderá informar o fato ao agente indústria, que por sua vez informará ao responsável pelo atendimento dos clientes grandes redes dentro da indústria.

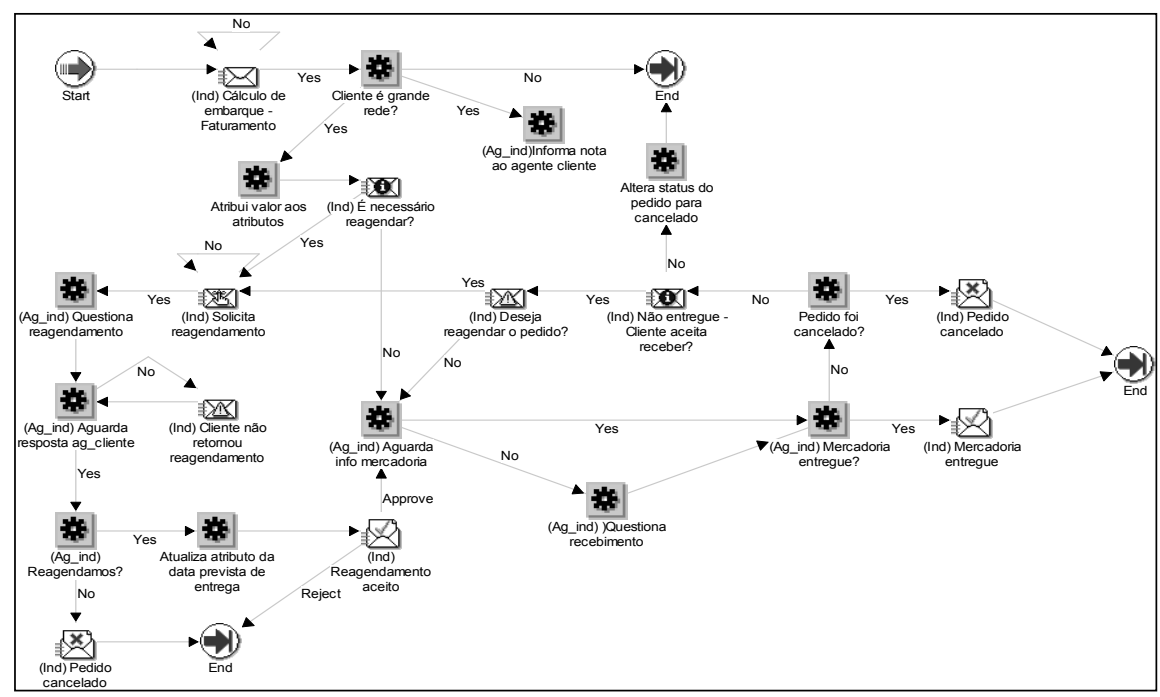

Figura 1. Workflow proposto 
A Tabela 2 apresenta uma explanação de algumas atividades ilustradas na Figura 3.

Tabela 2 - Descrição das atividades do workflow

\begin{tabular}{|c|}
\hline $\begin{array}{l}\text { Nome da Atividade: (Ag_ind) Informa nota ao agente cliente. } \\
\text { Descrição: A stored procedure chama_ag_ind chama o agente indústria que executa o co } \\
\text { informar nota. }\end{array}$ \\
\hline $\begin{array}{l}\text { Nome da Atividade: (Ag_ind) Aguarda informação da mercadoria. Tipo: Função. } \\
\text { Descrição: A stored procedure aguarda_info aguarda um retorno do agente indústria (através do seu } \\
\text { comportamento avisar) quanto ao recebimento ou não da mercadoria. Controla o tempo de espera } \\
\text { através da stored procedure. }\end{array}$ \\
\hline $\begin{array}{l}\text { Nome da Atividade: }(\mathrm{Ag} \text { _ind) Questiona recebimento. } \\
\text { Descrição: Disparada quando não há um retorno sobre o recebimento da mercadoria. A stored } \\
\text { procedure questiona_recebimento ativa o agente indústria que executa o seu comportamento } \\
\text { questionar_recebimento. }\end{array}$ \\
\hline Nome da Atividade: (Ind) Mercadoria entregue. $\quad$ Tipo: Notificação. \\
\hline
\end{tabular}

2.3. Critérios utilizados para a escolha das atividades desempenhadas pelos agentes Com base nos problemas levantados no estudo do fluxo de trabalho do setor de logística, são apresentados os critérios que levaram à escolha das atividades que serão executadas pelos agentes.

a) Evitar que ocorra recusa por atraso: A recusa de mercadoria por motivo de atraso na entrega em um cliente grande rede, pode ser evitada caso consiga-se proceder com o reagendamento da data de entrega em tempo hábil, ou seja, até a data de entrega original, o que acarretará na diminuição do trabalho humano e de despesas financeiras.

b) Receber informações sobre qualquer alteração no pedido quando as mesmas ocorrem: O cliente pode realizar o cancelamento do pedido mesmo sem a data de entrega ter expirado. Nesse caso, quanto antes a indústria for comunicada sobre o cancelamento, menor será a pendência originada. Por exemplo: o assistente pode evitar que a mercadoria saia da indústria ou, caso já tenha saído, pode informar o caso ao setor comercial, para que providencie um novo pedido ou uma recolocação de mercadoria.

c) Identificar problemas com antecedência: Tendo conhecimento do atraso de uma mercadoria, o assistente pode entrar em contato com a transportadora/agregado para verificar o motivo desse atraso. Esse contato permitirá que se descubra com antecedência algum problema que tenha ocorrido como, por exemplo, um sinistro. Como nesse caso é necessário enviar novamente a mercadoria, pode-se proceder com essa rotina de imediato. Se ocorrer um problema de recusa, o assistente poderá verificar o motivo entrando em contato imediatamente com o comprador, para buscar uma solução. Nesse caso, a pendência não pôde ser evitada, mais uma providência pôde ser tomada em menor tempo e sem maiores prejuízos.

d) Controlar as entregas para os clientes grandes redes: Atualmente, não é possível saber na data prevista para a entrega de uma mercadoria, se a mesma foi efetivamente entregue, a não ser que o assistente entre em contato com o cliente ou com a transportadora/agregado. Como ocorrem muitas entregas no mesmo dia, esse funcionário não dispõe de tempo para essas verificações, que podem ser realizadas pelos agentes.

e) Obter detalhes das entregas para os clientes grandes redes: No modelo atual de fluxo de trabalho da indústria, não se têm estatísticas de como são realizadas as entregas. Esse dado seria interessante para reconhecimento do perfil e avaliação do 
desempenho das transportadoras. Os agentes, além de monitorar as entregas, terão conhecimento sobre as entregas anteriores, podendo fornecer essas informações (por exemplo, número de entregas no prazo feitos por uma transportadora).

\subsection{Estratégia de controle de pendências}

A estratégia de controle de exceções realizadas pelos agentes foi representada utilizando o Diagrama de Casos de Uso. O diagrama ilustra os agentes e os demais papéis que compõem o modelo (como: assistente e transportadora), e exibe as atividades a serem desempenhadas pelos agentes na organização.

\subsubsection{Um exemplo de Casos de uso agente indústria e agente cliente}

A Figura 2 apresenta o diagrama de casos de uso agente indústria e agente cliente, onde é possível verificar as interações que ocorrem entre esses atores.

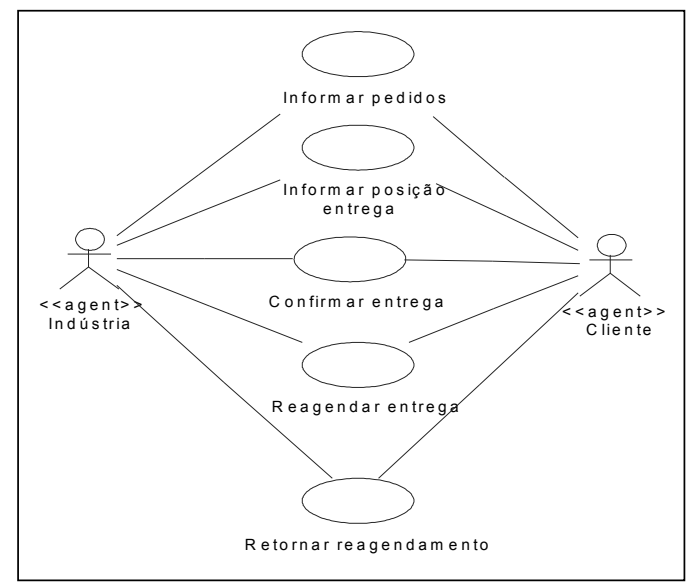

Figura 2. Diagrama de casos de uso agente indústria e agente cliente

\subsection{Classificação dos agentes do modelo}

$\mathrm{O}$ agente indústria está inserido no ambiente da indústria e o agente cliente no ambiente do cliente. Tais agentes possuem percepção do ambiente, pois recebem informações do seu ambiente (como o número do pedido). Também possuem conhecimento do ambiente, ou seja, conhecimento das informações sobre o pedido e podem ampliar o conhecimento através da comunicação com outro agente (por exemplo: o agente indústria pode comunicar ao agente cliente a necessidade de um reagendamento informando uma nova data). Tais agentes agem baseados em comportamentos.

Os agentes apresentam memória de fatos ocorridos anteriormente (lembrança de outros pedidos), capacidade de raciocínio com base em sua representação do ambiente (conhecimentos) e capacidade de decisão, analisando uma situação e escolhendo o comportamento que melhor atende a mesma (por exemplo: na data de entrega da mercadoria o agente indústria pode entrar em contato com o agente cliente, caso não tenha recebido nenhuma posição quanto a entrega da mercadoria).

Os agentes estão continuamente monitorando as entregas, fornecendo informações sobre as transportadoras (como: data efetiva da entrega no cliente pela transportadora). 


\subsection{Um exemplo de comportamento dos agentes}

A Tabela 3 ilustra os comportamentos definidos para o agente indústria. Um comportamento é selecionado a partir do conhecimento que o agente possui do ambiente, resultando em uma ação.

Tabela 3 - Comportamentos do agente indústria.

\begin{tabular}{|c|c|}
\hline \multicolumn{2}{|r|}{ Agente indústria } \\
\hline Comportamento & Descrição \\
\hline 1. Informar nota & Informar pedido faturado \\
\hline 2. Questionar reagendamento & Podemos reagendar a entrega? \\
\hline 3. Avisar assistente & $\begin{array}{l}\text { Cliente recebeu a mercadoria no prazo } \\
\text { Cliente não recebeu a mercadoria } \\
\text { Cliente cancelou o pedido } \\
\text { Cliente recusou a mercadoria } \\
\text { Cliente aceitou o reagendamento } \\
\text { Cliente recusou o reagendamento e cancelou o pedido }\end{array}$ \\
\hline 4. Questionar recebimento & Recebeu a mercadoria? \\
\hline 5. Responder & $\begin{array}{l}\text { A mercadoria será entregue hoje? } \\
\text { Ocorreu um sinistro }\end{array}$ \\
\hline 6. Gerar histórico & Entregas realizadas por transportadora \\
\hline
\end{tabular}

Aos agentes cabe a escolha adequada dos comportamentos para desempenhar as atividades para as quais foram alocados, visando atingir o objetivo que é manter o controle do processo, monitorando e evitando as pendências no processo de entrega de mercadoria.

\section{Implementação de um Ambiente de Simulação}

O modelo de workflow proposto inclui dois agentes independentes que atuam um do lado da indústria e outro do lado do cliente. $\mathrm{O}$ agente indústria atua no ambiente da indústria e trabalha em conjunto com o workflow. O agente cliente atua no ambiente do cliente e recebe as informações do agente indústria através da comunicação direta.

\subsection{Interação workflow - agente indústria}

$\mathrm{Na}$ modelagem do workflow na ferramenta Oracle Workflow Builder [WfMC 2005], foram previstas atividades a serem desempenhadas pelo agente indústria. A ferramenta trabalha com stored procedures e através delas foi possível ativar o agente.

Todas as respostas necessárias ao workflow e que o agente indústria recebe, como, por exemplo, a entrega da mercadoria, são armazenadas em uma tabela. $\mathrm{O}$ workflow, através de stored procedures, acessa essa tabela em busca dos dados necessários ao andamento do processo.

\subsection{Simulação do processo de entrega}

A seqüência de telas a seguir, ilustra um processo de entrega de mercadoria.

No momento em que uma nota de um cliente grande rede é inserida no sistema, o agente indústria é ativado e comunica essa informação ao agente cliente. A chamada ao agente indústria ocorre na função "(Ag_ind) Informa nota ao agente cliente", como apresentado na Figura 1. O agente indústria é chamado através de uma stored procedure. A função seguinte "Atribui valor aos atributos" é executada através de uma stored procedure e atualiza os atributos com os valores digitados no formulário de entrada da nota fiscal. 
Neste momento, o workflow passa para a atividade "(Ag_ind) Aguarda info mercadoria", onde uma stored procedure fica monitorando a tabela de comunicação entre o agente indústria e o workflow. O workflow permanece aguardando até que lhe seja informado, pelo agente indústria, um evento como: recebimento da mercadoria, recusa, cancelamento do pedido ou atraso na entrega, ou até que a hora marcada para a entrega, acrescida de um tempo de tolerância, seja excedida. Se o tempo de espera estourar, o agente indústria entra em contato com o agente cliente solicitando uma posição de entrega. $\mathrm{O}$ agente cliente possui o mesmo tipo de controle para verificar o status da nota que está aguardando, constatado um atraso, informa ao agente indústria.

Nessa simulação, o cliente avisou sobre o recebimento da mercadoria ao agente cliente, que por sua vez, informou ao agente indústria. $\mathrm{O}$ agente indústria informa ao workflow que então, envia uma notificação ao assistente, como ilustrada na Figura 3.

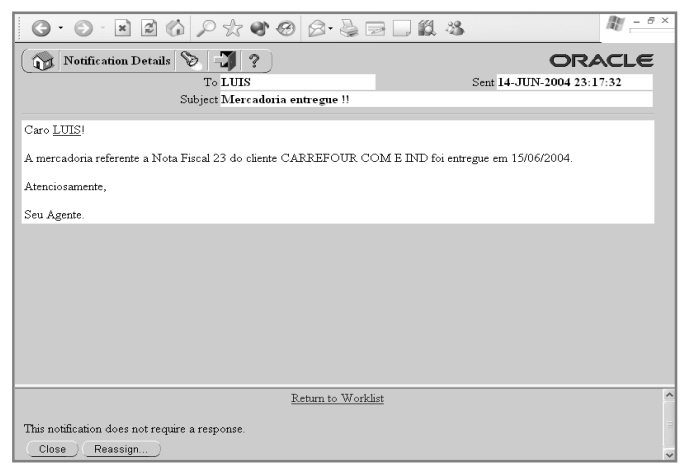

Figura 3. Notificação de entrega de mercadoria

A tela para visualização do processo é reduzida, por isso, o mesmo foi apresentando na Figura 4 (a) e na Figura 4 (b). É possível visualizar o caminho que o workflow percorreu até chegar ao final do processo.

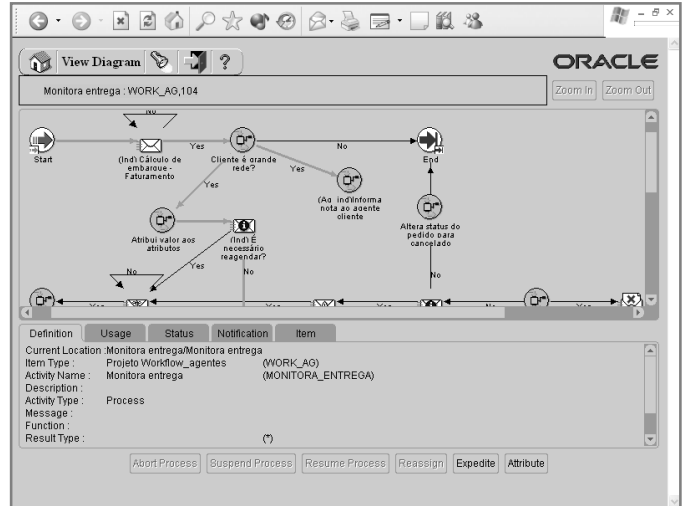

(a)

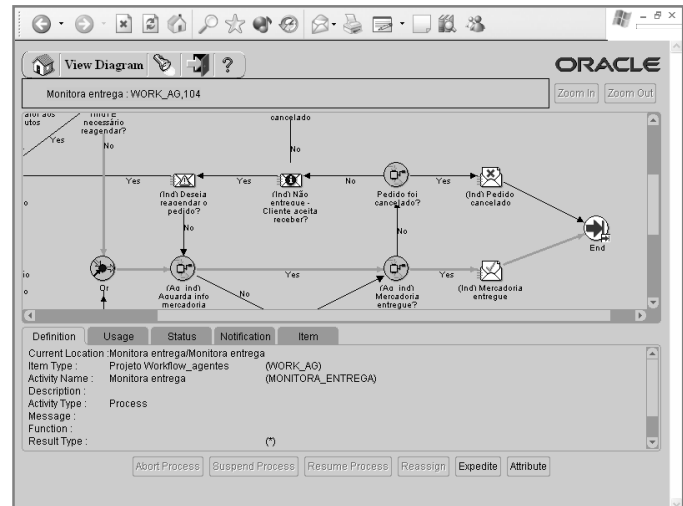

(b)

Figura 4. Visualização do processo

Através dos experimentos realizados pôde-se constatar que foi vantajosa a utilização dos agentes no workflow, pois os mesmos conseguiram atingir o seu objetivo principal que é o de evitar que ocorram recusas de mercadoria por atraso na entrega.

\section{Conclusão}

A aplicação de agentes, no controle de pendências geradas nos processos de workflow, busca evitar problemas de recusa de mercadoria e informar a indústria sobre outros 
problemas que possam ter ocorrido o mais rápido possível, trazendo, assim, benefícios para a organização. O principal objetivo deste trabalho foi apresentar a proposta de um modelo de workflow identificando de que forma os agentes poderiam evitar as pendências.

Através de um ambiente de simulação, pôde-se avaliar a atuação dos agentes no processo de entrega de mercadorias e apresentar as vantagens da incorporação de agentes ao processo de negócio, que são:

- delegar aos agentes funções que sobrecarregariam o trabalho de um funcionário;

- permitir maior controle por parte do setor de logística da indústria quanto às entregas de mercadorias aos clientes;

- permitir o conhecimento sobre as transportadorass contratadas pela indústria;

- auxiliar a indústria a atingir uma de suas metas: a entrega de mercadorias conforme data estabelecida com o cliente;

- proporcionar a previsão de uma pendência gerada por uma recusa de mercadoria, reduzindo assim o tempo de solução da pendência e conseqüentemente os custos;

- possibilitar que a indústria desenvolva um trabalho personalizado com os clientes (fornecendo o agente cliente), mostrando a sua preocupação não só no momento de produção da mercadoria, mais com todo o processo.

Dado a relação indústria/transportadora (ou agregado)/cliente, tornou-se interessante a incorporação de agentes ao domínio, como forma de integrar e evitar que a distância e a falta de comunicação entre tais entidades gerem situações indesejáveis, tomando uma ação no momento preciso. Esse ambiente distribuído proporcionou o uso de agentes. Desta forma, pôde-se concluir que a utilização de agentes pode auxiliar no processo de logística, evitando que problemas gerem tais pendências.

\section{Referências}

Cruz, Tadeu. (2003) Sistemas, Métodos \& Processos: administrando organizações por meio de processos de negócios. São Paulo: Atlas.

Cruz, Tadeu (2004) Workflow II: a tecnologia que revolucionou processos. Rio de Janeiro: E-Papers.

Frantz, F.; Bagatini, D. S.; Molz, K. (2005) Um Sistema Multiagente Aplicado a Processos de Negócios. In: Encontro Nacional de Inteligência Artificial (ENIA). São Leopoldo: UNISINOS.

Hübner, J. F. (2003) Um Modelo de Reorganização de Sistemas Multiagentes. São Paulo: Escola Politécnica da USP. Tese de Doutorado.

Juchem, M.; Bastos, R. M. (2002) Projetando Sistemas Multiagentes em Organizações Empresariais. In: Simpósio Brasileiro de Engenharia de Software. Gramado.

Ogliari, I.; Bagatini, D. S.; Frozza, R. (2005) Processo de alocação de recursos utilizando sistema multiagente. In: Encontro Nacional de Inteligência Artificial (ENIA). São Leopoldo: UNISINOS.

WfMC. (2005) “Workflow Management Coalition”, http://www.wfmc.org/, Setembro. 